\title{
Commentary: Judgment day: Should you add atrial fibrillation ablation?
}

\author{
Patrick M. McCarthy, MD
}

\author{
From the Division of Cardiac Surgery, Northwestern University Feinberg School of Medicine, Chicago, Ill. \\ Disclosures: P.M.M.: Edwards Lifesciences: consultant, royalties, intellectual property. Abbott Vascular: consul- \\ tant. Atricure: speaker. \\ Received for publication Nov 1, 2018; accepted for publication Nov 1, 2018; available ahead of print Dec 11, \\ 2018. \\ Address for reprints: Patrick M. McCarthy, MD, Division of Cardiac Surgery, Northwestern University Feinberg \\ School of Medicine, 201 East Huron St, Suite 11-140, Chicago, IL 60611-2908 (E-mail: pmccart@nm.org). \\ J Thorac Cardiovasc Surg 2019;157:1515-6 \\ $0022-5223 / \$ 36.00$ \\ Copyright (c) 2018 by The American Association for Thoracic Surgery \\ https://doi.org/10.1016/j.jtcvs.2018.11.004
}

Guideline Level 1 recommendations are intended as strong suggestions for how to treat the patient. For example, patients with degenerative mitral regurgitation with left ventricular dysfunction should have surgery unless there are unusual extenuating circumstances (eg, age/frailty or other life-limiting comorbidities), in which case the surgeon makes a judgment that the risk of surgery is higher than the benefit. In 2017, adding an atrial fibrillation (AF) ablation procedure for those patients with preexisting AF undergoing concomitant surgery was elevated to a Class 1 indication $^{1,2}$ even though none of the randomized clinical trials demonstrated an increase in survival or reduction in strokes compared with the control population. ${ }^{3-7}$ But freedom from AF was always better in the treated group.

Ad and coworkers ${ }^{8}$ have demonstrated that the 5-year freedom from AF of patients treated with AF ablation with a mitral valve procedure is similar when compared with AF ablation with coronary artery bypass (CAB) or aortic valve replacement (AVR), procedures that do not otherwise require a left atriotomy. Historically, only $15 \%$ to $30 \%$ of preoperative nonmitral surgery AF cases are treated with concomitant AF ablation. ${ }^{9}$ Will these data be enough to convince surgeons to add AF ablation to patients undergoing AVR or CAB? Probably not, because we need a wider context that is often missing from AF surgery reports: how often surgeons do not perform AF ablation. The 30-day morbidity and 5-year freedom from AF could be influenced by the patients that we choose not to treat with AF ablation. For instance, since 2013, I have performed AF ablation in $97 \%$ of patients undergoing mitral valve surgery with preoperative AF. I use cryoablation almost exclusively and therefore can quickly and effectively create the lesion set. I add ablation even though there may be multiple factors that may negatively affect late freedom from AF (eg, patients with more than 20 years AF duration, elderly patients, and those with a dilated atrium). On the other hand, I have treated only $73 \%$ of patients receiving AVR $\pm \mathrm{CAB}$ during that time. Sometimes, in my judgment, foregoing the AF

\section{References} 2003;24:475-80.

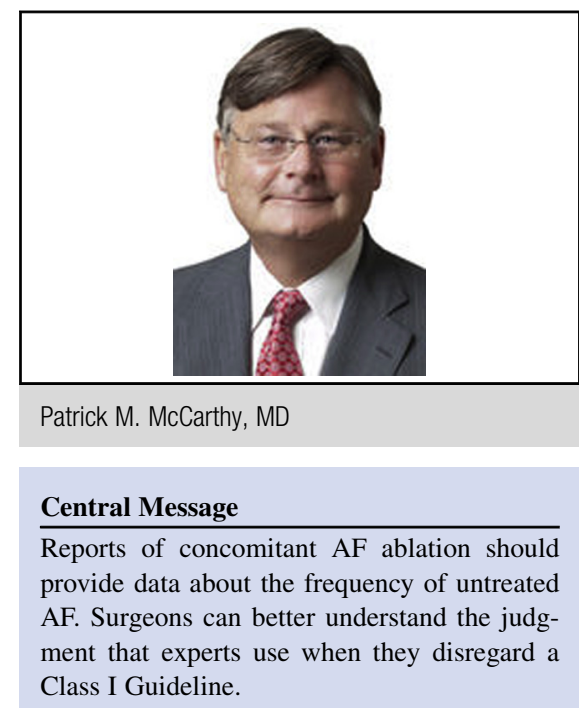

See Article page 1505 .

ablation may be a better choice. For example, when there is a concern that patent bypass grafts may be injured by a more extensive surgery or when I want to keep the bypass time as short as possible because of an elevated creatinine with a complex operation. The report from Ad and colleagues ${ }^{8}$ confirms good results when experienced surgeons decide to treat, but it does not help most surgeons make that critical decision on the day of surgery: Should you add AF ablation? Are surgeons ignoring the Class I Guidelines or are they using good judgment? We do not know. Reports that provide information on how often and why AF is not treated by expert surgeons like Dr Ad would be helpful guidance when making that judgment.

1. Calkins H, Hindricks G, Cappato R, Kim YH, Saad EB, Aguinaga L, et al. 2017 HRS/EHRA/ECAS/APHRS/SOLAECE expert consensus statement on catheter and surgical ablation of atrial fibrillation. Heart Rhythm. 2017;14:e275-444.

2. Badhwar V, Rankin JS, Damiano RJ Jr, Gillinov AM, Bakaeen FG, Edgerton JR, et al. The Society of Thoracic Surgeons 2017 clinical practice guidelines for the surgical treatment of atrial fibrillation. Ann Thorac Surg. 2017;103:329-41.

3. Gillinov AM, Gelijns AC, Parides MK, DeRose JJ Jr, Moskowitz AJ, Voisine P, et al. Surgical ablation of atrial fibrillation during mitral-valve surgery. $N$ Engl $J$ Med. 2015;372:1399-409.

4. Schuetz A, Schulze CJ, Sarvanakis KK, Mair H, Plazer H, Kilger E, et al. Surgical treatment of permanent atrial fibrillation using microwave energy ablation: a prospective randomized clinical trial. Eur J Cardiothorac Surg.

5. Doukas G, Samani NJ, Alexiou C, Oc M, Chin DT, Stafford PG, et al. Left atrial radiofrequency ablation during mitral valve surgery for continuous atrial fibrillation: a randomized controlled trial. JAMA. 2005;294:2323-9. 
6. Blomstrom-Lundqvist C, Johansson B, Berglin E, Nilsson L, Jensen SM, Thelin S, et al. A randomized double-blind study of epicardial left atrial cryoablation for permanent atrial fibrillation in patients undergoing mitral valve surgery: the SWEDish multicentre atrial fibrillation study (SWEDMAF). Eur Heart J. 2007;28:2902-8.

7. Badhwar V, Rankin JS, Ad N, Grau-Sepulveda M, Damiano RJ, Gillinov AM, et al. Surgical ablation of atrial fibrillation in the United States: trends and propensity matched outcomes. Ann Thorac Surg. 2017;104:493-500.
8. Ad N, Holmes SD, Rongione AJ, Badhwar V, Wei L, Fornaresio LM, et al. The long-term safety and efficacy of concomitant Cox maze procedures for atrial fibrillation in patients without mitral valve disease. J Thorac Cardiovasc Surg. 2019; 157:1505-14.

9. Ad N, Suri RM, Gammie JS, Sheng S, O’Brien SM, Henry L. Surgical ablation of atrial fibrillation trends and outcomes in North America. J Thorac Cardiovasc Surg. 2012;144:1051-60. 